\title{
Patient understanding of genetic information influences reproductive decision making in retinoblastoma
}

\begin{abstract}
A Foster $^{1}$, L Boyes ${ }^{1}$, L Burgess $^{1}$, S Carless $^{1}$, V Bowyer $^{1}$, H Jenkinson $^{2}$, M Parulekar $^{2}, \mathrm{~J}$ Ainsworth $^{2}$, J Hungerford ${ }^{3,4}$, Z Onadim $^{5}$, M Sagoo $^{3,4,6}$, E Rosser $^{3}$, MA Reddy $^{3,4}$, T Cole $^{1}$ ${ }^{1}$ Department of Clinical Genetics, Birmingham Women's Hospital NHS Foundation Trust, Birmingham, UK ${ }^{2}$ Birmingham Children's Hospital NHS Foundation Trust, Birmingham, UK ${ }^{3}$ Retinoblastoma Service, Royal London Hospital, Barts Health NHS Trust, London, UK ${ }^{4}$ Moorfields Eye Hospital NHS Trust, London, UK ${ }^{5}$ Retinoblastoma Genetic Screening Unit, Barts Health NHS Trust, London, UK ${ }^{6}$ UCL Institute of Ophthalmology, London, UK
\end{abstract}

Corresponding author: Dr Trevor Cole

Address: Clinical Genetics Unit, Birmingham Women's Hospital, Mindelsohn Way, Birmingham B15 2TG

Telephone 01216272630 Fax 01216272618

E-mail Trevor.Cole@,bwnft.nhs.uk

\section{CONFLICTS OF INTEREST}

The authors declare no conflict of interest.

\section{ACKNOWLEDGEMENTS}

The authors thank the Childhood Eye Cancer Trust (CHECT) for funding this study and the families for generously giving their time to participate. We also thank Monica Olarinde, Sheila Parkes and the National Registry of Childhood Tumours for administrative assistance, and Elizabeth Bradshaw and David Burns for their support in preparation of the manuscript. 
We would also like to acknowledge the late Judith Kingston, paediatric oncologist at Great Ormond Street Hospital, who contributed greatly to this work. 


\begin{abstract}
Retinoblastoma is the most common malignant tumour of the eye in childhood, with nearly all bilateral tumours and around $17-18 \%$ of unilateral tumours due to an oncogenic mutation in the RB1 gene in the germline. Genetic testing in all cases enables accurate risk assessment and optimal clinical management for the affected individual, siblings, and future offspring. We carried out the first UK-wide audit of understanding of genetic testing in individuals with retinoblastoma. A total of 292 individuals aged 16-45 years were included.

Patients with bilateral disease were significantly more likely to understand the implications of retinoblastoma for siblings and children. There was a significant association between not knowing the results of genetic testing or not understanding the implications and not having children, particularly in women. Surprisingly, this was also true for individuals treated for unilateral disease with a low risk of retinoblastoma for their offspring.

We are concerned that individuals may be making life choices based on insufficient information regarding risks of retinoblastoma and reproductive options. We suggest that improvement in transition care is needed to enable individuals to make informed reproductive decisions and to ensure optimal care for children born at risk of retinoblastoma.
\end{abstract}

KEY WORDS: genetic screening/counselling, paediatric oncology; RB1, retinoblastoma; transition care

\title{
INTRODUCTION
}

Retinoblastoma is the most common malignant tumour of the eye in childhood, affecting approximately 1:20,000 live births ${ }^{1}$. It occurs in differentiating cone precursor cells of the 
developing retina that have predisposing mutations in both copies of the tumour suppressor gene $\mathrm{RB} 1^{2-4}$.

Retinoblastoma is bilateral in about $40 \%$ of cases with a median age of diagnosis of 12 months ${ }^{5}$. The other $60 \%$ of affected individuals have unilateral retinoblastoma with a median age of diagnosis of 24 months. Nearly all cases of bilateral retinoblastoma, and $17-18 \%$ of cases of unilateral retinoblastoma $^{6,7}$, are due to an inherited or de novo heterozygous germline mutation in RB1 and are therefore subsequently hereditary segregating in an autosomal dominant pattern. The remainder of the bilateral cases and some unilateral cases are caused by mosaicism for a mutation, which may be present in the germline. Around $83 \%$ of unilateral retinoblastoma is non-hereditary, occurring due to somatic mutations in both copies of RB1 in the same retinal cell. The heritability of retinoblastoma determines the risks of retinoblastoma for siblings and children of the affected individual, which vary from $<1 \%$ to $50 \%$ based on empiric data ${ }^{7,8}$.

Current molecular genetic screening techniques detect up to $95 \%$ of germline RB1 mutations in leucocytes of individuals with hereditary retinoblastoma ${ }^{7,9}$. Identifying whether or not an individual has hereditary retinoblastoma is essential for appropriate clinical management, determining the need for frequent follow up examination under anaesthesia (EUA) for early detection of newly arising tumours.

Molecular genetic testing is also essential for optimal management of other family members. Detection of a germline RB1 mutation antenatally or postnatally identifies babies at a high risk of developing retinoblastoma who will benefit from intensive ophthalmic surveillance from birth (Table S1 for Birmingham Children's Hospital High Risk Screening Protocol). Frequent examinations including EUAs enable timely detection of tumours, reducing the likelihood that enucleation, radiotherapy, and/or chemotherapy will be required, and helping preserve vision and reduce morbidity. Babies who are found not to have inherited the familial 
RB1 mutation do not require ophthalmic surveillance, avoiding unnecessary and burdensome EUA and the attendant risks of anaesthesia. In a small number of cases with unilateral retinoblastoma where it cannot be proven that the disease is not germline a modified screening protocol is followed for the siblings and offspring of the affected family member (Table S1 for Birmingham Children's Hospital Low Risk Screening Protocol). Identification of a germline RB1 mutation also enables new reproductive options such as pre-implantation genetic diagnosis (PGD) to be offered.

Genetic testing is therefore essential for individuals with retinoblastoma to have accurate and up to date information for their own clinical management and for that of their children and other family members. As part of the standard management of retinoblastoma, it should be performed in all individuals irrespective of whether the retinoblastoma is bilateral or unilateral, and in this latter group should always include molecular studies on the retinoblastoma tumour, where this is available. In this paper we describe the first UK national audit assessing individuals' understanding of the genetic implications of their retinoblastoma diagnosis.

Currently all patients with retinoblastoma in the UK are treated at one of the two nationally funded retinoblastoma services. In 1990 a designated national retinoblastoma service was commissioned at St Bartholomew's Hospital in London. Prior to this date, some cases, especially isolated unilateral cases would have been managed in local services. Care of patients in the West Midlands continued to be provided at the Birmingham Children's Hospital and this became the second national service in 2002. From this date all new cases of retinoblastoma were managed by the multi-disciplinary teams (paediatric ophthalmology, paediatric oncology, clinical and laboratory genetics, clinical psychology and appropriate related specialities) at one or other of these two services. 


\section{MATERIALS AND METHODS}

\section{Data collection}

Patients seen in Birmingham were identified from the West Midlands Regional Children's Tumour Registry (WMRCTR) and patients seen in London were identified from local clinical records and all cases cross-checked on the National Registry of Childhood Tumours (NRCT). The details of all surviving patients diagnosed with retinoblastoma between 1957 and 2008 were reviewed. Those individuals aged 16 to 45 at the initiation of the project in 2009 were contacted over a three year period 2009 to 2012. The general practitioners (GPs) of all identified individuals were approached to confirm that it was appropriate to contact the patient regarding the audit. Following this initial contact, questionnaire forms were sent out to each individual (see Fig. 1). Two versions of the form were sent out (see supplemental information Fig. S1), one addressed to the individual (Form A) and the other addressed to the parents of the individual with retinoblastoma (Form B). Each family decided which questionnaire was the most appropriate to complete. Where a family returned more than one questionnaire, as occurred in a very small number of cases, this was readily detectable to the authors by matching the names. Where this occurred the information reported by the patient rather than the relative was used, as this was the key information the audit was aiming to assess. The questions aimed to gather information on individuals' understanding of the risk of retinoblastoma for family members, namely siblings (both forms) and children (Form A only). All respondees were asked if they wanted a follow up appointment to go over this information and if requested an appointment with their local clinical genetics service was 
arranged. Following discussion with a local ethics committee member this was deemed to be an audit assessing the past implementation of standard clinical practice, not research, and therefore formal review by an ethics committee was not required.

Audit Interpretation

Each questionnaire was given an 'Audit Interpretation' (AI) assessment of the individual's understanding of the genetic implications of their retinoblastoma based on the answers they gave to the questions regarding the risk of retinoblastoma for siblings and children. The data recorded was the individuals 'own understanding' of the retinoblastoma risk and may be different to that which was imparted to them, which in many circumstances may be via a third party such as their parents, or several different doctors over a period of time. The AI was deemed to be 'Correct', 'Incorrect', 'No information' if risks were not given, 'Out of date' if the risk given was based on out of date information, or 'Unable to assess' if the true risk was impossible to ascertain based on the clinical information available from the questionnaire. All questionnaires were assessed by an experienced genetic counsellor (LB, LB, or SC) and verified by a second author single author (TC). There were a very small number of cases where a difference of opinion arose. These cases were discussed within the genetic counselling and consultant team and a consensus arrived at in all cases.

\section{Exclusion criteria}

Individuals under 16 years of age and older than 45 were excluded for the purposes of this audit analysis, which was to assess individuals' reproductive knowledge at the current time. Individuals younger than 16 would most likely have future genetic counselling planned at transition or in adulthood and those older than 45 were considered unlikely to be planning further children. 
Individuals who did not specify whether their retinoblastoma was unilateral or bilateral were also excluded from data analysis.

\section{Laterality}

Cases were grouped into bilateral, hereditary unilateral and non-hereditary unilateral. The unilateral cases are divided into hereditary and non-hereditary based on reported family history and therefore the true percentage of hereditary cases in the unilateral group will be higher due to undetected de novo germline mutations. Throughout the paper, the term 'nonhereditary unilateral' refers to the presumed non-hereditary cases.

The small number of hereditary unilateral cases are considered as a separate group as although the risk of children inheriting the RB1 mutation is $50 \%$ as in the bilateral cases, the penetrance is much lower. Furthermore, their perception of the significance of unilateral disease is likely to be different from those individuals with bilateral disease, having significantly less impact for visual impairment and a lower risk for second nonretinoblastoma primary tumours.

Statistics

GraphPad software was used to perform Chi-square testing and Fisher's exact test in statistical analysis of the data.

\section{RESULTS}

\section{Demographics and laterality}


575 letters were sent to GPs and 569 replies were received. In six cases it was deemed not appropriate to contact the patient and a total of 563 patient letters were sent out. There were 471 respondents (return rate 84\%). 108 were under 16 years of age and 29 were older than 45 and were therefore excluded. Another 42 individuals did not specify whether their retinoblastoma was unilateral or bilateral and were also excluded from data analysis. A total of 292 individuals aged 16-45 were therefore included (Fig. 1). Out of these, 230 of the questionnaires were completed by individuals themselves and 60 were completed on behalf on the individual with retinoblastoma by a parent or guardian. In two cases it was unclear whether the individual or a third party had completed the form. These cases were excluded from analyses requiring AI but were otherwise included in the results. At the time of participation in the audit, $46 \%(135 / 292)$ were aged $16-25$ years old, $27 \%(79 / 292)$ were aged 26-35 years old and 27\% (78/292) were aged 36-45 years old. The median age was 26 years and the mean 28.2 years. Form A respondents were older (median 29 years mean 29.7 years) than Form B respondents (median 19 years mean 22.7 years). 53\% (156/292) were female and $47 \%(136 / 292)$ male. The laterality of retinoblastoma was 34\% (100/292) with bilateral disease and 66\% (192/292) with unilateral disease. In the unilateral group, 5\% (9/192) reported a family history of retinoblastoma. In the bilateral group, $25 \%$ reported a family history of retinoblastoma (Table 1).

\section{Genetic testing rates}

Individuals with bilateral disease were significantly more likely to report having undergone genetic testing than those with non-hereditary unilateral disease: $68 \%(68 / 100)$ vs. $36 \%$ $(65 / 183)(\mathrm{p}<0.001$, Chi-square test). However, when testing had been performed, individuals from both groups were equally likely to recall having received the results of testing, with 
$82 \%(56 / 68)$ of the bilateral group and $85 \%(55 / 65)$ of the non-hereditary unilateral group knowing the results of genetic tests.

\section{Understanding of genetic test results}

In the bilateral group 77\% (53 of the 69 individuals who completed Form A) reported that they knew the risk of retinoblastoma for their children and 41\% (41/100) for their siblings. These figures were significantly lower in the non-hereditary unilateral group, with only $31 \%$ (47 of the 153 individuals who completed Form A) aware of the risks for children and 17\% $(31 / 183)$ for siblings $(\mathrm{p}<0.001$, Chi-square test).

Only $72 \%$ (63/88, excluding out of date/unable to assess/blank responses) of individuals with bilateral disease were given an AI score of 'Correct' for understanding the genetic implications of retinoblastoma, and only $30 \%$ (46/154, excluding out of date/unable to assess/blank responses) of individuals with non-hereditary unilateral disease. Seven individuals in the non-hereditary unilateral group overestimated the risk of retinoblastoma for their children as $50 \%$.

Individuals who had undergone genetic testing and received the results of their tests were significantly more likely to correctly assess the chance of retinoblastoma for siblings and/or children. $88 \%$ of those with bilateral disease (46/52, excluding unable to assess/out of date/blank) who knew the results of their genetic tests understood the genetic implications for siblings and/or children, compared to only $47 \%$ (17/36, excluding unable to assess/out of date/blank) of those who did not undergo genetic testing, or had genetic testing and did not know the result of testing $(\mathrm{p}<0.001 \mathrm{Chi}$-square test). In the non-hereditary unilateral group, $63 \%$ (29/46, excluding unable to assess/out of date/blank) of those who had undergone testing and received results understood the genetic implications for siblings and children, compared to only $16 \%(17 / 108$, excluding unable to assess/out of date/blank) of those who 
did not undergo testing or had testing and did not know the result $(\mathrm{p}<0.001$ Chi-square test). (Table 2)

\section{Requests for appointments to discuss risks for other family members}

Overall 30\% (88/292) of individuals requested an appointment to discuss the risk of retinoblastoma for other family members: $27 \%(27 / 100)$ of the bilateral group and $32 \%$ $(58 / 183)$ of the non-hereditary unilateral group. In the bilateral group, a significantly greater proportion $(39 \%, 17 / 44)$ of those who did not know the results of genetic testing requested an appointment compared to only $18 \%(10 / 56)$ of those who knew the results of genetic testing $(p=0.0360$, Chi-square test). Similarly in the non-hereditary unilateral group, $40 \%(51 / 128)$ of those who did not know the results of genetic testing requested an appointment compared to only $13 \%(7 / 55)$ of those who knew the results of genetic testing $(\mathrm{p}=0.0006)$ (Table 2$)$.

\section{Follow up}

In the bilateral group, $48 \%(48 / 100)$ and in the non-hereditary unilateral group $14 \%(25 / 183)$ reported attending a long-term follow up clinic with ophthalmology or oncology. Of those not under follow up, $48 \%$ (24/50, excluding two not answered) in the bilateral group and $45 \%$ $(71 / 158)$ in the non-hereditary unilateral group requested follow up in a retinoblastoma clinic. In the bilateral group, $60 \%$ of individuals aged 16-25 were under long term follow up compared to $44 \%$ in the $26-35$ years age group and $34 \%$ of those age $36-45$ years.

\section{Reproduction}


67 of the 230 individuals who completed Form A reported having had children (29\%), 3\% (3/88) of the $16-25$ age group, $35 \%$ of the $26-35$ age group (25/72), and $56 \%(39 / 70)$ of the 36-45 age group. Overall there was no significant difference in fertility rate between the bilateral and non-hereditary unilateral groups (bilateral 19/69, 28\%; unilateral 45/153, 29\%; $p=0.775$, Chi-square test). A greater proportion of the 36-45 age group with non-hereditary unilateral disease had children compared to the same age individuals with bilateral disease $(26 / 3967 \%$ vs $11 / 2642 \%)$ but this was not a statistically significant difference $(p=0.3$, Chisquare test).

Individuals who knew the results of genetic testing were significantly more likely to have children compared to those who did not know results of genetic testing in the bilateral group (16/42 vs $3 / 27 p=0.0255$, Fisher's exact test) and the non-hereditary unilateral group $(23 / 45$ vs $22 / 108 p=0.0004$, Fisher's exact test) (Table 2). Individuals who understood the risks of retinoblastoma for their children and siblings were significantly more likely to have children than those who did not in both the bilateral group (17/48 vs 0/15 $\mathrm{p}=0.0063$, Fisher's exact test) and in the non-hereditary unilateral group (23/40 vs $18 / 91 p=0.0001$, Fisher's exact test) There was no significant difference in fertility between men and women (41/136 women, 26/94 men $\mathrm{p}=0.7944$ Chi-square test).

Women who knew the results of genetic testing were significantly more likely to have children than those who did not (31/64 vs 10/72 p<0.0001 Chi square test) (Fig. 5). This was true in both the bilateral and non-hereditary unilateral groups (bilateral $11 / 28$ vs $0 / 17$ $p=0.0031$ Fisher's exact test; non-hereditary unilateral $19 / 34$ vs 9/52 $p=0.0003$ Fisher's exact test).Of note, none of the women in the bilateral group who were unaware of their genetic test results had children.

Understanding the genetic implications of retinoblastoma was also significantly associated with having children in both groups (bilateral 11/32 vs 0/10 p=0.0411 Fisher's exact test; 
non-hereditary unilateral 14/24 vs 7/42 p=0.0008 Fisher's exact test, excluding out of date/unable to assess/blank). Women in the bilateral group who did not understand the genetic implications of retinoblastoma did not have children.

There was a trend towards men being more likely to have children if the results of genetic testing were known, but this was not statistically significant (10/27 vs $16 / 67 p=0.300$ Chi square test) and this was true for both bilateral and non-hereditary unilateral groups (bilateral 5/14 vs 3/10 p=1 Fisher's exact test, non-hereditary unilateral 4/11 vs 13/56 p=0.45 Fishers' exact test) (Fig. 5). Men with non-hereditary unilateral disease who understood the genetic implications of retinoblastoma were more likely to have children than those who did not understand the genetic implications of retinoblastoma (8/15 vs 8/44 Fisher's exact test $\mathrm{p}=0.016$, excluding out of date/unable to assess/blank). Men with bilateral disease who did not understand the genetic implications did not have children ( $0 / 5$ vs $6 / 16$ excluding out of date/unable to assess/blank) however the numbers here are very small.

\section{DISCUSSION}

\section{Rates of genetic testing}

Overall, the audit found that reported rates of genetic testing were surprisingly low in both unilateral and bilateral groups. Part of the explanation for this is that genetic testing only became routinely available in the mid to late 1990s for bilateral retinoblastoma and even later for unilateral retinoblastoma. The participants in the audit were all born before 1995 and therefore would not have been offered testing at the time of diagnosis, and would have had to be offered or seek testing at a later date. It is now routine practice to offer genetic testing in all cases of retinoblastoma. 
An additional potential reason for low reported rates of genetic testing is that because of the natural history of retinoblastoma, patients will be diagnosed and undergo testing in childhood, and therefore as adults may be unaware of previous genetic testing. It is possible that in some cases, parents might have withheld information from a child in an effort to protect the child from worrisome news. Knowledge of having had a genetic test depends on this information being passed on by a parent, or through a follow up appointment in adolescence or adulthood with the healthcare system.

\section{Understanding of genetic test results}

Individuals with bilateral retinoblastoma were more likely to be able to give accurate risks for siblings and children. This may be due to the fact that genetic test results in unilateral retinoblastoma are more likely to be incomplete or uninformative and more complicated than in bilateral disease and therefore assessing risk is more complex. In addition, as patients with unilateral retinoblastoma are usually discharged from national follow up before the early teenage years, individuals may be reliant solely on their parents for the communication of this information. However even in bilateral retinoblastoma, where assessment of recurrence risk is straightforward and individuals might be expected to be in long-term follow up, over a quarter of individuals were not able to correctly assess the recurrence risks for their siblings and children. Less than half of individuals with bilateral retinoblastoma in the audit reported attending a long-term follow up clinic, suggesting that many individuals rely on their parents as a source of information. Previous research has identified a number of reasons why communication of genetic information in retinoblastoma from parent to child may fail, including the difficulty of recalling information received at a time that is very stressful, and in some cases a reluctance to discuss issues around genetic risk ${ }^{10}$. 
$\underline{\text { Requests for appointments to discuss risks for other family members }}$

The results indicated that a number of individuals who did not know their genetic test results or risks to family members wished to have this information and requested an appointment with clinical genetics. The study has enabled these individuals to access this information through appointments with their local clinical genetics service. The identification that $40 \%$ of responders in the single largest group (unilateral non hereditary without genetic information) requested an appointment identifies a significant unmet need. This is especially concerning in the group that are at mostly at low risk of having an affected child.

\section{Follow up}

Long term follow up for retinoblastoma in the UK is typically organised back with the referring centre, especially for unilateral disease. It should however include oncology input in a 'late effects' service for those who had bilateral disease or any case that required either chemotherapy or radiotherapy. $48 \%$ of individuals with bilateral retinoblastoma and $14 \%$ of those with unilateral retinoblastoma reported being under long-term follow-up. Of those individuals not currently under follow up with oncology or ophthalmology, almost half requested that this be arranged. This was true for both unilateral and bilateral groups, indicating a clear desire by adults with retinoblastoma for ongoing medical follow up.

\section{Reproduction}

Overall a surprisingly low proportion of the cohort reported having children, for example $38 \%(14 / 37)$ of women in the $36-45$ years age group did not have children compared to $19 \%$ of 45 year old women in the general population in the $\mathrm{UK}^{11}$. We identified a clear relationship between genetic testing and understanding the genetic implications of retinoblastoma and 
having children in both unilateral and bilateral groups, which was especially striking in female participants. From the audit data we cannot identify the cause and effect. The association may be due to individuals wanting children actively seeking out genetic testing; alternatively, it may be that individuals who are unaware of therisks and reproductive choices are deciding not to have children. Our finding that over $80 \%(43 / 52)$ of women with nonhereditary unilateral retinoblastoma who were unaware of genetic test results had no children might suggest that it is the lack of genetic information that is influencing reproductive decisions.

Previous work exploring reproductive decision making in retinoblastoma has identified patient perception of risk as an important factor. Dommering et al. found that retinoblastoma had a significant impact on reproductive behaviour in a cohort of patients who had undergone genetic testing, with perceived risk as opposed to actual risk being the most important factor $^{12,13}$. A study of other inherited retinal disorders identified that affected individuals had a deep anxiety about passing on visual impairment to their children, and some had chosen not to have children because the risk was 'too high"14.

We must also consider that a lack of clinical information patients have regarding developments in treatment of retinoblastoma and an "unawareness" of better outcomes compared to the past might be influencing individuals' decisions not to have children. Many children under surveillance because of an identified risk of retinoblastoma will now be treated by local therapy only (e.g. laser/cryotherapy) and avoid the morbidity associated with enucleation, chemotherapy and/or external beam radiotherapy. Individuals who have experienced the morbidity associated with older treatments may choose not to have children to avoid side effects they feel are unacceptable and not be aware of these new therapies. Follow up in a late effects clinic would give patients the opportunity to discuss future management and outcomes. 
A lack of information regarding new reproductive technologies such as PGD may also be playing an important role. We found $100 \%$ of women with bilateral retinoblastoma who did not know their genetic test results had no children, a highly surprising figure. This may reflect a lack of awareness of the options now available that enable individuals to have children without retinoblastoma and anecdotal evidence of this was seen in the audit. There are potentially other confounding factors, such as social factors, body image, and selfesteem issues that may be related to facial asymmetry or visual impairment, many of which will be avoided with newer treatment, but which may still be influencing reproductive rates in individuals with retinoblastoma. Further investigation, ideally through a qualitative research study, is warranted to explore the reasons for the low reproductive rates in individuals with retinoblastoma identified by this study.

The results of this large scale national audit suggest that individuals may be making life choices based on incomplete or inaccurate information. It is vital for health care professionals to ensure young adults who were diagnosed with retinoblastoma in childhood have up to date genetic test results and fully understand the implications of these results. This is necessary to inform their own medical care, to enable them to make informed reproductive decisions, and to ensure that optimal care is provided to children who are born at risk of retinoblastoma. In this era of mainstreaming genetics we must ensure that embedding clinical genetics in transition care is seen as a priority. 


\section{REFERENCES}

1 MacCarthy a, Birch JM, Draper GJ, et al. Retinoblastoma in Great Britain 1963-2002. Br J Ophthalmol 2009; 93: 33-7.

2 Friend SH, Bernards R, Rogelj S, et al. A human DNA segment with properties of the gene that predisposes to retinoblastoma and osteosarcoma. Nature 1986; 323: 643-6.

3 Knudson AG. Mutation and cancer: statistical study of retinoblastoma. Proc Natl Acad Sci U S A 1971; 68: 820-823.

$4 \mathrm{Xu} \mathrm{X}$, Singh $\mathrm{H}$, Wang L, et al. Rb suppresses human cone precursor-derived retinoblastoma tumors. Nature 2014; 16: 385-388.

5 Aerts I, Lumbroso-Le Rouic L, Gauthier-Villars M, Brisse H, Doz F, Desjardins, L. Retinoblastoma. Orphanet Journal of Rare Diseases 2006; 1: 31.

6 Lohmann DR, Gerick M, Brandt B, et al. Constitutional RB1-gene mutations in patients with isolated unilateral retinoblastoma. Am J Hum Genet 1997; 61: 282-294.

7 Price EA, Price K, Kolkiewicz K, et al. Spectrum of RB1 mutations identified in 403 retinoblastoma patients. J Med Genet 2014; 51: 208-214.

8 Rushlow D, Piovesan B, Zhang K, et al. Detection of mosaic RB1 mutations in families with retinoblastoma. Hum Mutat 2009; 30: 842-51. 
9 Richter S, Vandezande K, Chen N, et al. Sensitive and efficient detection of RB1 gene mutations enhances care for families with retinoblastoma. Am J Hum Genet 2003; 72: 253-69.

10 Clarke S, Sheppard L, Eiser C. Mothers' Explanations of Communicating Past Health and Future Risks to Survivors of Childhood Cancer. Clin Child Psychol Psychiatry 2008; 13: 157-170.

11 Oliver Dormon. Statistical Bulletin: Cohort Fertility, 2012. Off Natl Stat 2013.

12 Dommering CJ, van den Heuvel MR, Moll AC, Imhof SM, Meijers-Heijboer H, Henneman L. Reproductive decision-making: a qualitative study among couples at increased risk of having a child with retinoblastoma. Clin Genet 2010; 78: 334-41.

13 Dommering CJ, Garvelink MM, Moll a C, et al. Reproductive behavior of individuals with increased risk of having a child with retinoblastoma. Clin Genet 2012; 81: 21623.

14 Potrata B, McKibbin M, Lim JN, Hewison J. 'To perpetuate blindness!': attitudes of UK patients with inherited retinal disease towards genetic testing. $J$ Community Genet 2014; 5: 215-22.

\section{LEGENDS}

Figure 1. Flowchart of participant inclusion and exclusion 
Figure 2 The percentage of respondents who had children. Knowing the results of genetic testing was significantly associated with having children in female respondents but not male respondents.

Figure S1. Questionnaires sent to participants, Forms A and B 
FIGURE 1: Flowchart of participant inclusion and exclusion

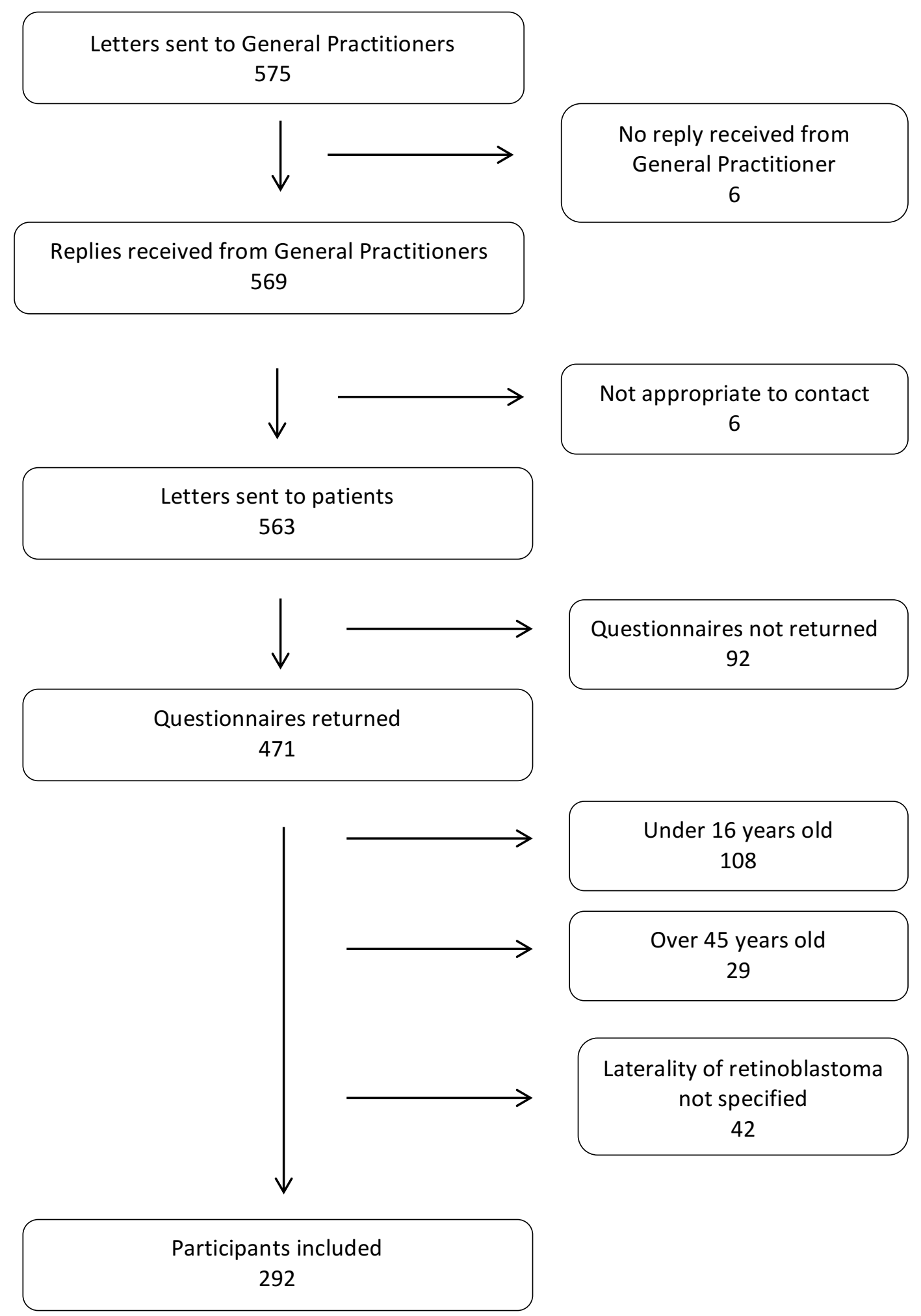


FIGURE 2

Male Female

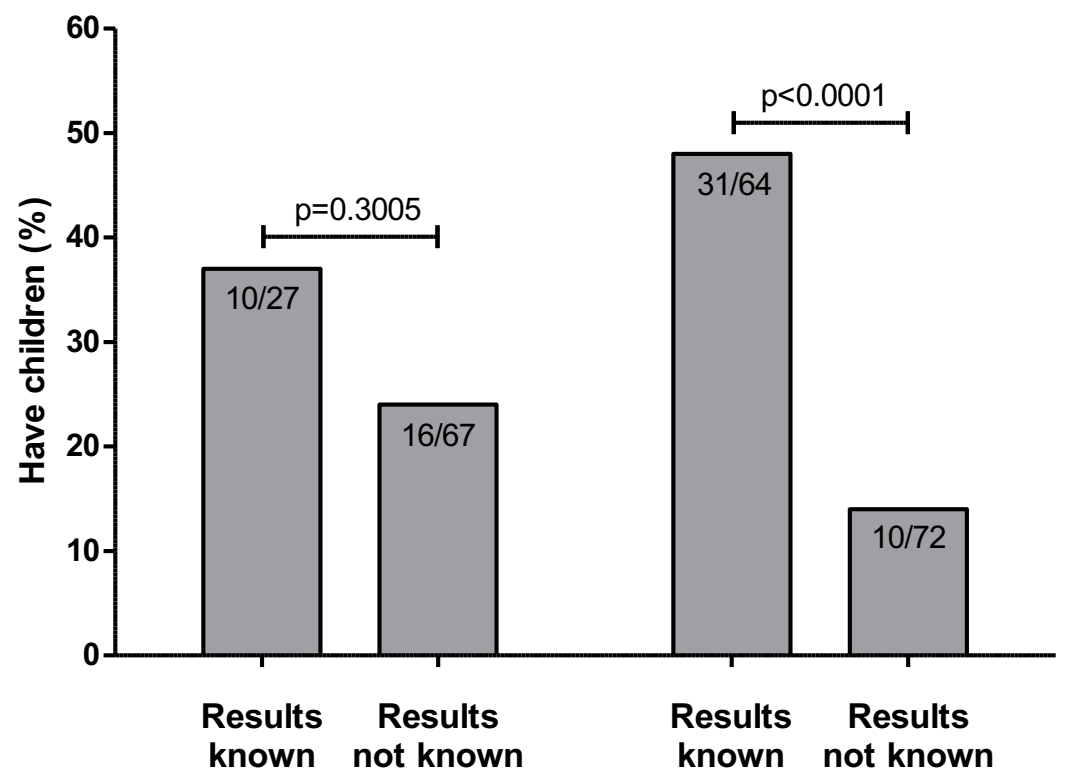




\section{FIGURE S1}

Questionnaires

\section{FORM A}

Personal details

Name

Sex: $\mathrm{M} / \mathrm{F}$

Date of birth
a. Age when retinoblastoma was diagnosed
b. Mother's date of birth
c. Father's date of birth

Q1. Which eyes are affected? Right eye only / Left eye only / Both eyes / Don't know

Q2. Have both your parents had their eyes checked to exclude a healed/regressed retinoblastoma (scar on the back of the eye)? Yes / No / Don't know

Q3. Has anybody else in the family had a retinoblastoma? Yes / No / Don't know

Q4. Have you had blood taken for a gene test? Yes (go to Q5) / No (go to Q7) / Don't know (go to Q7)

Q5. When was the gene test carried out?

Q6. Have you had the result of the gene test? Yes / No / Don't know

Q7. Do you have any children? Yes (go to Q8) / No (go to Q9)

Q8. Please enter your children's details

\begin{tabular}{|l|l|l|l|l|l|}
\hline Name & Sex & $\begin{array}{l}\text { Current } \\
\text { age }\end{array}$ & $\begin{array}{l}\text { Have they had a } \\
\text { gene test? }\end{array}$ & $\begin{array}{l}\text { Have they had } \\
\text { eye exams? }\end{array}$ & $\begin{array}{l}\text { Have they had a } \\
\text { retinoblastoma? }\end{array}$ \\
\hline & M/F & & $\begin{array}{l}\text { Yes/No/Don't } \\
\text { know }\end{array}$ & $\begin{array}{l}\text { Yes/No/Don't } \\
\text { know }\end{array}$ & Yes/No/Don't know \\
\hline M/F & M/F & $\begin{array}{l}\text { Yes/No/Don't } \\
\text { know }\end{array}$ & $\begin{array}{l}\text { Yes/No/Don't } \\
\text { know }\end{array}$ & Yes/No/Don't know \\
know & & $\begin{array}{l}\text { Yes/No/Don't } \\
\text { know }\end{array}$ & Yes/No/Don't know \\
\hline
\end{tabular}




\begin{tabular}{|l|l|l|l|l|l|}
\hline & M/F & $\begin{array}{l}\text { Yes/No/Don't } \\
\text { know }\end{array}$ & $\begin{array}{l}\text { Yes/No/Don't } \\
\text { know }\end{array}$ & Yes/No/Don't know \\
\hline M/F & $\begin{array}{l}\text { Yes/No/Don't } \\
\text { know }\end{array}$ & $\begin{array}{l}\text { Yes/No/Don't } \\
\text { know }\end{array}$ & Yes/No/Don't know \\
\hline
\end{tabular}

Q9. Do you know how likely retinoblastoma is for your current / any future children? Yes (go to Q10) / No (go to Q11) / Don't know (go to Q11)

Q.10 Please tick the box that you think best describes the chance that your current / any future children will develop retinoblastoma: $5 \%$ or less ( 1 in 20 chance) / 50\% (1 in 2 chance) / close to $100 \%$ (almost certain to) / Don't know

Q11. Do you have any brother or sisters? Yes (go to Q12) / No (go to Q15) / Don't know (go to Q15)

Q12. Please enter your brothers' / sisters' details below

\begin{tabular}{|l|l|l|l|l|l|}
\hline Name & Sex & $\begin{array}{l}\text { Current } \\
\text { age }\end{array}$ & $\begin{array}{l}\text { Have they had a } \\
\text { gene test? }\end{array}$ & $\begin{array}{l}\text { Have they had } \\
\text { eye exams? }\end{array}$ & $\begin{array}{l}\text { Have they had a } \\
\text { retinoblastoma? }\end{array}$ \\
\hline & M/F & & $\begin{array}{l}\text { Yes/No/Don't } \\
\text { know }\end{array}$ & $\begin{array}{l}\text { Yes/No/Don't } \\
\text { know }\end{array}$ & Yes/No/Don't know \\
\hline & M/F & & $\begin{array}{l}\text { Yes/No/Don't } \\
\text { know }\end{array}$ & $\begin{array}{l}\text { Yes/No/Don't } \\
\text { know }\end{array}$ & Yes/No/Don't know \\
\hline & M/F & & $\begin{array}{l}\text { Yes/No/Don't } \\
\text { know }\end{array}$ & $\begin{array}{l}\text { Yes/No/Don't } \\
\text { know }\end{array}$ & Yes/No/Don't know \\
\hline & M/F & $\begin{array}{l}\text { Yes/No/Don't } \\
\text { know }\end{array}$ & $\begin{array}{l}\text { Yes/No/Don't } \\
\text { know }\end{array}$ & Yes/No/Don't know \\
& & $\begin{array}{l}\text { Yes/No/Don't } \\
\text { know }\end{array}$ & $\begin{array}{l}\text { Yes/No/Don't } \\
\text { know }\end{array}$ & Yes/No/Don't know \\
\hline
\end{tabular}

Q13. Do you know how likely retinoblastoma was for your brothers / sisters? Yes (go to Q14) / No (go to Q15) / Don't know (go to Q15)

Q14. Please tick the box that you think best describes the chance that any of your brothers/sisters named above would develop a retinoblastoma: 5\% or less ( 1 in 20 chance) / $50 \%$ ( 1 in 2 chance) / close to $100 \%$ (almost certain to) / Don't know Q15. Would you like an appointment to go over any of this information? Yes / No 
Q16. Are you aware of any pregnancies in the family that were the result of assisted reproductive techniques, such as egg or sperm donation or IVF (test tube pregnancy)? Yes / No / Don’t know

Q17. Are you attending a long-term follow up clinic (either Ophthalmology or Oncology)? Yes / No

Q18. The current national recommendations are for some patients, diagnosed with retinoblastoma, to receive regular outpatient appointments, even into adulthood. If you are not on any form of follow up - would you like an appointment in a retinoblastoma follow-up clinic to be arranged?

Please use this space to add further information: 


\section{FORM B}

Details of person with retinoblastoma

Name

Sex: $M / F$

Date of birth

Age when retinoblastoma was diagnosed

Mother's date of birth

Father's date of birth

Details of person completing this form

Name

Relationship to person with retinoblastoma

Q1. Which eyes are affected in the person with retinoblastoma? Right eye only / Left eye only / Both eyes / Don't know

Q2. Have both parents had their eyes checked to exclude a healed/regressed retinoblastoma (scar on the back of the eye)? Yes / No / Don't know

Q3. Has anybody else in the family had a retinoblastoma? Yes / No / Don't know

Q4. Has blood been taken from the person with retinoblastoma for a gene test? Yes (go to Q5) / No (go to Q7) / Don't know (go to Q7)

Q5. When was the gene test carried out?

Q6. Have you had the result of the gene test? Yes / No / Don't know

Q7. Does the person with retinoblastoma have any brothers or sisters? Yes (go to Q8) / No (go to Q11)

Q8. Please enter the brothers'/sisters' details below

\begin{tabular}{|c|c|c|c|c|c|}
\hline Name & Sex & $\begin{array}{l}\text { Current } \\
\text { age }\end{array}$ & $\begin{array}{l}\text { Have they had a } \\
\text { gene test? }\end{array}$ & $\begin{array}{l}\text { Have they had } \\
\text { eye exams? }\end{array}$ & $\begin{array}{l}\text { Have they had a } \\
\text { retinoblastoma? }\end{array}$ \\
\hline & $\mathrm{M} / \mathrm{F}$ & & $\begin{array}{l}\text { Yes/No/Don’t } \\
\text { know }\end{array}$ & $\begin{array}{l}\text { Yes/No/Don't } \\
\text { know }\end{array}$ & Yes/No/Don't know \\
\hline & $\mathrm{M} / \mathrm{F}$ & & $\begin{array}{l}\text { Yes/No/Don't } \\
\text { know }\end{array}$ & $\begin{array}{l}\text { Yes/No/Don't } \\
\text { know }\end{array}$ & Yes/No/Don't know \\
\hline & $\mathrm{M} / \mathrm{F}$ & & $\begin{array}{l}\text { Yes/No/Don't } \\
\text { know }\end{array}$ & $\begin{array}{l}\text { Yes/No/Don't } \\
\text { know }\end{array}$ & Yes/No/Don't know \\
\hline
\end{tabular}




\begin{tabular}{|l|l|l|l|l|l|}
\hline & M/F & $\begin{array}{l}\text { Yes/No/Don't } \\
\text { know }\end{array}$ & $\begin{array}{l}\text { Yes/No/Don't } \\
\text { know }\end{array}$ & Yes/No/Don't know \\
\hline M/F & $\begin{array}{l}\text { Yes/No/Don't } \\
\text { know }\end{array}$ & $\begin{array}{l}\text { Yes/No/Don't } \\
\text { know }\end{array}$ & Yes/No/Don't know \\
\hline
\end{tabular}

Q9. Do you know how likely it is that any current/future brothers or sisters would develop a retinoblastoma? Yes (go to Q10) / No (go to Q11) / Don't know (go to Q11)

Q10. Please tick the box that you think best describes the chance that any current / future brothers or sisters would develop a retinoblastoma: $5 \%$ or less ( 1 in 20 chance) $/ 50 \%$ (1 in 2 chance) / close to $100 \%$ (almost certain to) / Don't know

Q11. Would you like an appointment to go over any of this information? Yes / No

Q12. Are you aware of any pregnancies in the family that were the result of assisted reproductive techniques, such as egg or sperm donation or IVF (test tube pregnancy)? Yes / No / Don't know

Q13. Are you attending a long-term follow up clinic (either Ophthalmology or Oncology)? Yes / No

Q14. The current national recommendations are for some patients, diagnosed with retinoblastoma, to receive regular outpatient appointments, even into adulthood. If you are not on any form of follow up - would you like an appointment in a retinoblastoma follow-up clinic to be arranged?

Please use this space to add further information: 
Table 1: Summary of results

\begin{tabular}{|c|c|c|c|c|}
\hline & Bilateral & $\begin{array}{c}\text { Non-hereditary } \\
\text { unilateral }\end{array}$ & $\begin{array}{c}\text { Hereditary } \\
\text { unilateral }\end{array}$ & Total \\
\hline Number of individuals & 100 & 183 & 9 & 292 \\
\hline \multicolumn{5}{|l|}{ Form completed* } \\
\hline Form A & 69 & 153 & 8 & 230 \\
\hline Form B & 31 & 28 & 1 & 60 \\
\hline \multicolumn{5}{|l|}{ Sex } \\
\hline Male & 44 & 88 & 4 & 136 \\
\hline Female & 56 & 95 & 5 & 156 \\
\hline \multicolumn{5}{|l|}{ Age } \\
\hline $16-25$ & 43 & 90 & 2 & 135 \\
\hline $26-35$ & 25 & 52 & 2 & 79 \\
\hline $36-45$ & 32 & 41 & 5 & 78 \\
\hline \multicolumn{5}{|l|}{ Family history $\mathrm{Rb}$} \\
\hline - & 25 & 0 & 9 & 34 \\
\hline No & 72 & 171 & 0 & 243 \\
\hline Don't know & 3 & 12 & 0 & 15 \\
\hline \multicolumn{5}{|l|}{ Genetic testing performed } \\
\hline 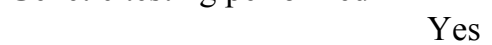 & 68 & 65 & 6 & 139 \\
\hline No & 20 & 83 & 1 & 104 \\
\hline Don't know & 12 & 33 & 2 & 47 \\
\hline Not answered & 0 & 2 & 0 & 2 \\
\hline \multicolumn{5}{|l|}{ Result of genetic test known } \\
\hline Yes & 56 & 55 & 5 & 116 \\
\hline No & 5 & 12 & 2 & 19 \\
\hline Don't know & 8 & 8 & 0 & 16 \\
\hline Not answered & 31 & 108 & 2 & 141 \\
\hline \multicolumn{5}{|l|}{$\begin{array}{l}\text { Know how likely } \mathrm{Rb} \text { is for } \\
\text { children^}{ }^{\wedge}\end{array}$} \\
\hline 然 & 53 & 47 & 5 & 105 \\
\hline No & 10 & 65 & 0 & 75 \\
\hline Don't know & 6 & 40 & 3 & 49 \\
\hline Not answered & 0 & 1 & 0 & 1 \\
\hline \multicolumn{5}{|l|}{$\begin{array}{l}\text { Know how likely } \mathrm{Rb} \text { is for } \\
\text { siblings }\end{array}$} \\
\hline 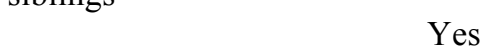 & 41 & 31 & 4 & 76 \\
\hline No & 27 & 79 & 1 & 107 \\
\hline Don't know & 16 & 58 & 3 & 77 \\
\hline Not answered & 16 & 15 & 1 & 32 \\
\hline \multicolumn{5}{|l|}{ Would like an appointment } \\
\hline 1 & 27 & 58 & 3 & 88 \\
\hline No & 62 & 113 & 5 & 180 \\
\hline Not answered & 11 & 12 & 1 & 24 \\
\hline \multicolumn{5}{|l|}{ Attending long-term follow up } \\
\hline Yes & 48 & 25 & 2 & 75 \\
\hline No & 50 & 157 & 7 & 214 \\
\hline Not answered & 2 & 1 & 0 & 3 \\
\hline \multicolumn{5}{|l|}{ Would like to be under follow up } \\
\hline Yes & 30 & 81 & 4 & 115 \\
\hline No & 34 & 76 & 4 & 114 \\
\hline Not answered & 36 & 26 & 1 & 63 \\
\hline \multicolumn{5}{|l|}{ Have children ${ }^{\wedge}$} \\
\hline Yes & 19 & 45 & 3 & 67 \\
\hline No & 49 & 106 & 5 & 160 \\
\hline Not answered & 1 & 2 & 0 & 3 \\
\hline
\end{tabular}

$*_{\text {in }}$ two cases in was unclear whether the individual or a third party had completed the form

$\wedge$ Form A respondees only 
Table 2: Respondents who knew their genetic test results were significantly more likely to correctly assess the risk of retinoblastoma for siblings and/or children, significantly less likely to request a review appointment with clinical genetics, and significantly more likely to have children than those who did not know their genetic test results

\begin{tabular}{|l|l|c|c|}
\hline & Bilateral disease & $\begin{array}{c}\text { Non-hereditary } \\
\text { unilateral disease }\end{array}$ \\
\hline \multirow{2}{*}{$\begin{array}{l}\text { Genetic } \\
\text { test results } \\
\text { known }\end{array}$} & Correct understanding of implications for & $46 / 52$ & $29 / 46$ \\
& siblings and/or children & $(88 \%)$ & $(63 \%)$ \\
\cline { 2 - 4 } & Requested review appointment with & $10 / 56$ & $7 / 55$ \\
& clinical genetics & $(18 \%)$ & $(13 \%)$ \\
\cline { 2 - 4 } & Had children & $16 / 42$ & $23 / 45$ \\
\hline \multirow{2}{*}{$\begin{array}{l}\text { Genetic } \\
\text { test results }\end{array}$ not known } & Correct understanding of implications for & $(38 \%)$ & $(51 \%)$ \\
\cline { 2 - 4 } & family members & $17 / 36$ & $17 / 108$ \\
& Requested review appointment with & $147 \%)$ & $(16 \%)$ \\
\cline { 2 - 4 } & clinical genetics & $(39 \%)$ & $51 / 128$ \\
\cline { 2 - 4 } & Had children & $3 / 27$ & $22 / 108$ \\
\cline { 2 - 4 } & & $(11 \%)$ & $(20 \%)$ \\
\hline
\end{tabular}


Table S1: Birmingham Children's Hospital NHS Foundation Trust protocols for screening siblings and offspring of patients with retinoblastoma

\begin{tabular}{|l|l|}
\hline AGE & HIGH RISK SCREENING PROTOCOL \\
\hline & Dilated fundus examination \\
\hline Within a week of birth & Awake examination, no anaesthetic \\
\hline 1 week -6 months & Monthly awake examination, no anaesthetic \\
\hline 6 months -2 years & Examination every 2 months \\
\hline 2 years -3 years & Examination every 3 months \\
\hline 3 years -4 years & Examination every 4 months \\
\hline 4 years -7 years & Examination every 6 months \\
\hline
\end{tabular}

\begin{tabular}{|l|l|}
\hline AGE & LOW RISK SCREENING PROTOCOL \\
\hline Within a week of birth & Dilated fundus examination \\
\hline 1 week -6 months & Awake examination, no anaesthetic \\
\hline 6 months -3 years & Examination every 3 months with EUA at least every 6 months \\
\hline 3 years -5 years & $\begin{array}{l}\text { Examination every } 6 \text { months -Most examinations will be undertaken } \\
\text { without anaesthetic, but clinical priority remains exclusion of } \\
\text { retinoblastoma, so the ophthalmologist may still feel EUA's } \\
\text { indicated at some points on the protocol for some individuals }\end{array}$ \\
\hline
\end{tabular}


